\title{
Laparoscopic Heller Myotomy for Achalasia: Experience from a Single Referral Tertiary Center
}

\author{
Alireza Mirsharifi ${ }^{1}$, Ali Ghorbani Abdehgah ${ }^{2, *}$, Rasoul Mirsharifi ${ }^{3}$, Mehdi Jafari ${ }^{4}$, \\ Noor Fattah ${ }^{1}$, Javad Mikaeli ${ }^{5}$, Ahmad Reza Soroush ${ }^{2}$
}

1. Tehran University of Medical Sciences, Department of General Surgery, Shariati Hospital, Tehran, Iran

2. Tehran University of Medical Sciences, Department of Surgery, Research Center of Surgical Outcomes and Procedures, Shariati Hospital, Tehran, Iran

3. Tehran University of Medical Sciences, Department of General Surgery, Imam Khomeini Hospital, Tehran, Iran

4. Tehran University of Medical Sciences, Department of Surgery, Research Center of Surgical Outcomes and Procedures, Shariati Hospital, Tehran, Iran

5. Digestive Disease Research Center, Tehran University of Medical Sciences, Shariati Hospital, Tehran, Iran

* Corresponding Author:

Ali Ghorbani Abdehgah, MD Surgery Ward, Shariati Hospital, Jalal Al-e-Ahmad Highway, Tehran, Iran Telefax: + 982184902450 Email: ghorbaniabdehgahali@gmail.com

Received: 02 Sep. 2018 Accepted: 20 Jan. 2019

\section{ABSTRACT}

\section{BACKGROUND}

Achalasia is the most well known esophageal motility disorder. Laparoscopic Heller myotomy (LHM) is the most effective treatment for achalasia. The aim of this study was to review our results on LHM for achalasia.

\section{METHODS}

In this cross-sectional study all patients undergoing LHM between 2015 and 2017 were studied. The myotomy was followed by an anterior or posterior partial fundoplication. All patients were followed up for at least six months.

\section{RESULTS}

We conducted this prospective study on 36 consecutive patients who underwent LHM over 3 years. The mean age of the patients was $36.64 \pm 13.47$ years. 30 patients $(83.3 \%)$ underwent Toupet and 6 patients $(16.7 \%)$ received Dor fundoplication. 11 patients $(30.6 \%)$ developed reflux after the procedure. According to the Eckardt Symptom Scoring (ESS), the symptoms improved in $74.2 \%$ of the patients and remained unchanged in $25.8 \%$ of the patients. Analysis of the ESS, indicated a significant change in regurgitation and retrosternal pain, dysphagia, and weight loss after the surgery ( $p=0.001, p=0.002, p=0.046$, and $p=0.001$, respectively).

\section{CONCLUSION}

LHM with anterior or posterior partial fundoplication is safe and achieves a good outcome in the treatment of achalasia, especially in patients who have not responded to other methods while no serious complication was reported despite several prior endoscopic interventions.

\section{KEYWORDS:}

Heller myotomy, Achalasia, Tertiary center, Laparoscopy, Botulinum toxin, Complication

Please cite this paper as:

Mirsharifi AR, Ghorbani Abdehgah A, Mirsharifi R, Jafari M, Fattah N, Mikaeli J, Soroush AR. Laparoscopic Heller Myotomy for Achalasia: Experience from a Single Referral Tertiary Center. Middle East J Dig Dis 2019;11:90-97. doi: 10.15171/mejdd.2018.133.

\section{INTRODUCTION}

Achalasia is the most well known esophageal motility disorder ${ }^{1}$ with an annual incidence of 1 in 100,000 and the prevalence of 8 in 10,000 people. The prevalence is equal in men and women., ${ }^{2,3}$ Idiopathic achalasia is a primary esophageal motor disorder characterized by the absence of peristalsis in esophageal body and abnormal relaxation of the lower esophageal sphincter (LES) in response to swallowing. The primary cause of achalasia is unknown. The symptoms of achalasia include dysphagia to solid foods and liquids, regurgitation, and chest pain. Barium swallow and endoscopic manometry are used to make a 
diagnosis of achalasia, which show aperistalsis, increased LES pressure, and failure of the LES to relax. ${ }^{4,5}$

Non-surgical treatment of achalasia includes the use of botulinum toxin injection, calcium channel blocker, and pneumatic balloon dilatation (PBD) of the LES; nevertheless, no medical or surgical treatment has been able to offer complete resolution of the disease. ${ }^{5}$ Pneumatic balloon dilation is usually effective, but surgical methods are used if; it fails to relieve symptoms, the patients do not accept the 3-5\% risk of esophageal perforation, and in young patients in whom the success rate of balloon dilation is relatively low. On the other hand, surgery provides a longer asymptomatic period compared with PBD. ${ }^{5,6}$

The disease is usually presented in younger ages, and delayed treatment may result in more serious complications including esophageal cancer. ${ }^{4}$ Although modern endoscopic surgical interventions and per oral endoscopic myotomy are increasingly used for treating achalasia, the preferred surgical method is still laparoscopic myotomy as an accepted intervention. ${ }^{7,8}$ Therefore, in line with other scientific centers worldwide, it is required to evaluate and present the treatment outcomes of this surgery in Iran. Hence, this study was conducted to evaluate the treatment outcomes and determinants of laparoscopic Heller myotomy (LHM) in patients with esophageal achalasia.

\section{MATERIALS AND METHODS}

This cross-sectional study was conducted in Shariati Hospital, Tehran, Iran from 2015 to 2017 after obtaining ethical approval (code: IR.TUMS.MEDICINE. REC.1395.861). The study was conducted on all patients with achalasia who underwent laparoscopic esophagomyotomy between 2015 and 2017. Manometry and esophagogastrography were used to make the diagnosis of achalasia.

Inclusion criteria: Patients with the diagnosis of achalasia according to clinical manifestations, manometric criteria, and imaging studies regardless of age were included in the study.

Exclusion criteria: Patients with a history of surgery as the treatment of achalasia, treatment plans other than surgery, or surgical methods other than LHM were excluded from the study.
The patients were asked for complete history of any previous treatments such as PBD or botulinum toxin injection.

After obtaining informed consents, the patients underwent LHM. The procedure was done in supine split-leg position. After intubation, nasogastric tube was placed to decompress the stomach. The first supraumbilical port insertion was performed in Hasson technic and followed by inserting four other ports (one right subcostal port, two left subcostal ports, and one subxiphoid port). ${ }^{9}$ After releasing the esophagophrenic ligament, the esophagus was retracted using a Penrose drain. Blunt dissection of the muscles from the esophageal mucosa was done by a 5-mm curved LigaSure or by shearing muscle layer where there was mucosal adhesion. Myotomy was performed for about 7-10 cm (at least $2 \mathrm{~cm}$ below gastroesophageal junction), and then a Dor or Toupet fundoplication was done at the surgeon's preference. After releasing the gastric fundus and short gastric vessels by the LigaSure, two sutures (Prolene 0-2) were used to anchor the right edge of myotomy to the dissected muscles and right diaphragmatic crus. The same technique was used on the left side, as well. The nasogastric tube was then removed after the procedure. If the patient had no signs and symptoms suggesting surgical complications, a liquid diet would be started on the first postoperative day followed by soft foods as tolerated. Operative, and postoperative findings, and unexpected events such as perforations, cardiovascular events, fever, NPO (nil per os) time, and duration of hospital stay were recorded for each patient. The patients received PPIs (proton pump inhibitors) for one to two months postoperatively as a routine and were on a soft diet for 2-4 weeks after the procedure. The patients were then evaluated in in-person visits or through telephone follow-ups to complete a checklist in the sixth month after surgery. It was tried at its best to follow-up at the same time for all the cases, but in few cases this follow up interval prolonged due to missing track of the patients for up to 24 months.

Based on the presenting signs and symptoms, the patients were scored for dysphagia, retrosternal pain, regurgitation, and recent weight loss based on the Eckardt Symptom Score 10 (table 1). Score $\geq 4$ is indicated as failure of symptom relief (treatment failure) and a score $\leq 3$ was indicated as treatment success. The scoring system 
Table 1: Eckardt symptom score

\begin{tabular}{lcccc}
\hline Score & Weight loss & Dysphagia & Retrosternal pain & Regurgitation \\
\hline 0 & None & None & None & None \\
\hline 1 & $<5 \mathrm{~kg}$ & Occasionally & Occasionally & Occasionally \\
\hline 2 & $5-10 \mathrm{~kg}$ & Daily & Daily & Daily \\
\hline 3 & $>10 \mathrm{~kg}$ & Each meal & Each meal & Each meal \\
\hline
\end{tabular}

is defined as $0=$ none, $1=$ occasionally, $2=$ daily, and $3=$ each meal for signs/symptoms and $0=$ none, $1=$ less than $5 \mathrm{Kg}, 2=5-10 \mathrm{Kg}$, and $3=$ more than $10 \mathrm{Kg}$ for recent weight loss (6 months). ${ }^{11}$

Based on the patients' satisfaction, they were divided to two groups of improved and non-improved according to their self-expression.

Statistical analysis: The SPSS software version 22 was used for data analysis. Quantitative data are presented as mean and standard deviation, and qualitative data are presented as frequency (percentage). T and Chi square tests were used to compare quantitative and qualitative data, respectively. To assess the scores of Eckardt variables, extended McNemar's test (Bowker's test) was used to compare pre and post-operative status and StuartMaxwell test was used to evaluate borderline homogeneity. Independent $t$ test was applied to assess the mean age in "improved" and "non-improved" groups. Chi square and Mann-Whitney U tests were employed to assess the correlation between improvement and sex and duration of symptoms before surgery, respectively. The level of significance was considered as $\alpha=0.05$ in all tests.

\section{RESULTS}

In this study, operative factors, postoperative outcomes, and correlation of other clinical factors with outcomes were assessed in 36 patients with achalasia including 19 women (52.8\%) and 17 men (47.2\%), who underwent laparoscopic esophagocardiomyotomy. The mean age of the patients was 36.64 years (range: 17-64 years). Five patients were lost in follow-up, so outcome results were analyzed based on 31 patients. The mean age of the participants was $36.6 \pm 13.4$ years. The most common manifestation was dysphagia $(n=33)$, pain $(n=3)$, regurgitation $(n=2)$, and cough $(n=1)$. The mean time interval between the onset of symptoms and the first visit was 64.1 months (range: 7-238 months).
Nine patients $(25 \%)$ had a history of botulinum toxin injection in cardia. In these patients, the mean interval between the last injection and surgery was 13.3 months (range:6-24 months). 30 patients (83.3\%) underwent Toupet and six patients (16.7\%) received Dor fundoplication. The mean duration of NPO time was $1.44 \pm 1.08$ days (range: 1-6 days). 11 patients $(30.6 \%)$ reported symptoms of reflux after the procedure, which were not proven objectively. The mean duration of hospital admissions was $4.4 \pm 1.5$ days. According to the Eckardt Symptom Scoring, which was done in 6-24 months, the symptoms improved in $74.2 \%$ of the patients and remained unchanged in $25.8 \%$ of the patients (treatment failure).

Analysis of the Eckardt Symptom Scores, which shows pre and postoperative changes, resulted that dysphagia that was reported in 31 patients, was subsided in five patients completely and 17 patients relatively after going through operation for at least 6 months but the remaining four patients did not report any difference in dysphagia and five patients reported worsening in dysphagia from daily pattern to each meal. Therefore $70.9 \%$ of the patients experienced improvement in dysphagia, which is statistically significant ( $p=0.001)$.

Retrosternal Pain was reported in 23 patients before operation. Eight patients reported complete recovery from pain and six patients reported relative recovery in at least 6 months after operation. Whereas seven patients reported no change. One patient reported more frequent pain post operatively, which can be explained by gastroesophageal reflux. Therefore the effectiveness of operation for retrosternal pain was $63.6 \%(p=0.047)$.

Regurgitation was reported in 29 patients, of whom 19 patients reported complete recovery and nine patients reported relative recovery from regurgitation in at least 6 months post operation. It was worsened in one patient and one patient who did not have regurgitation pre operatively, developed regurgitation after operation. The success 
rate of this operation in patients with regurgitation was $96.5 \%$, which is statistically significant ( $p=<0.001$ ).

27 out of the total 31 patients reported weight loss before operation, of whom 16 patients had less than $5 \mathrm{~kg}$, five patients had $5-10 \mathrm{~kg}$, and six patients had more than $10 \mathrm{~kg}$ weight loss preoperatively. 12 out of the 27 patients reported a weight gain of at least $5 \mathrm{~kg}$ post operation in less than 6 months whereas weight loss of more than 5 $\mathrm{kg}$ was reported in four patients post operatively. The remaining patients had no change in their weight (based on Eckardt). In other words, any amount of weight gain was achieved in 22 cases of $31,(1-22 \mathrm{~kg}$, mean $=5.9 \mathrm{~kg})$ based on the weight recorded in the follow-up period. Six cases had weight loss of any amount $(3-7 \mathrm{~kg}$ mean $=$ $5.5 \mathrm{~kg}$ ). It accounts for $44.5 \%$ for weight gain based on Eckardt score, and $70 \%$ based on weight changes (any amount) ( $p=0.002$, table 2 ).

Statistical analysis showed no significant correlation between the disease outcome and frequency of balloon dilation, history of botulinum toxin injection, age, and sex ( $p=0.078, p=0.128, p=0.870$, and $p=0.302$ ) (table 3).

According to the operative notes and follow-up result, $77.8 \%$ had no complication (including intraoperative and postoperative complications). The most common complication, was esophageal perforation $(n=4)$ followed by gastric perforation $(n=1)$. Post-operative complications include abdominal pain, cardiovascular events, and fever $(\mathrm{n}=1$ for each). All patients were asymptomatic regarding complications at the time of discharge. No adverse effect in final outcome was found in any complicated cases.

As for the overall improvement according to the patients' self-expression checklist (the patients gave a score of 1-10 to their satisfaction with the results of surgery as 1-4: satisfactory, 5-7: acceptable, 8-10: unsatisfactory), $25.8 \%$ of the patients were not satisfied with the surgical results while $74.2 \%$ reported that the results were acceptable. The mean age of the patients was 33.6 \pm 12.1 years in the improved and $34.7 \pm 11.4$ years in the non-improved groups. Statistical analysis showed no significant difference in the mean age between the two groups $(p=0.621)$.

Perforation had a significant positive correlation with a history of botulinum toxin injection $(p=0.05)$, time between last botulinum toxin injection and surgery $(p=$ 0.009), NPO time, and duration of antibiotic therapy, while no correlation was observed between perforation and history of pneumatic dilation, age, and $\operatorname{sex}(p>0.05)$ (table 4$)$.

\section{DISCUSSION}

According to the results of this study, regurgitation, retrosternal pain, dysphagia, and weight loss improved significantly in 6 months after the operation $(p=0.001$, $p=0.047, p=0.001$, and $p=0.002$, respectively).

According to the patients' self-expression, 23 patients (74.2\%) experienced an acceptable improvement in the symptoms and did not require any other treatments. According to the Eckardt Symptom Score, the symptoms improved in 23 patients $(74.2 \%)$ and remained unchanged in eight patients $(25.8 \%)$.

Hunter and colleagues evaluated the results of myotomy in 40 patients. Dysphagia and regurgitation improved in $36(90 \%)$ and $38(95 \%)$ patients, respectively. Retrosternal pain and heart burn also improved significantly and weight loss was reversed, which is consistent with our results. ${ }^{12}$

On the contrary, Moonen and co-workers conducted a clinical trial to compare pneumatic dilation and LHM. The results showed that after at least 5 years follow-up, there was no significant difference in esophageal function and emptying between these two treatment methods. However, only $25 \%$ of patients who underwent pneumatic dilation required re-dilation. Therefore, the authors concluded that either method could be used as an initial treatment for achalasia. These findings are consistent with the results of similar studies, especially a review study by Ines. ${ }^{13,14}$

In present study, postoperative symptoms improvement (based on the Eckardt symptom score) and patients' satisfaction had no significant correlation with age, sex, manometric parameters, botulinum toxin injection, and pneumatic dilation ( $p>0.05$ for all). In another study by Popoff and colleagues in 51 patients with achalasia who underwent Heller myotomy and Toupet fundoplication, dysphagia, retrosternal pain, heart burn, and regurgitation improved in $63 \%, 12 \%, 27 \%$, and $22 \%$ of the patients, respectively. Moreover, $80 \%$ of the patients reported that their overall satisfaction with the procedure was either excellent or good, and 90\% stated that they would undergo surgery again. The results of that study are consistent with our findings. ${ }^{15}$ 
Table 2: Comparison of Eckardt symptom scores

\begin{tabular}{|c|c|c|c|c|c|c|c|c|}
\hline \multicolumn{6}{|c|}{ Postoperative symptoms } & \multirow{2}{*}{ Total } & \multirow{2}{*}{$\begin{array}{c}P \text { value } \\
\text { Maxwell }\end{array}$} & \multirow{2}{*}{$\begin{array}{l}P \text { value } \\
\text { bucker }\end{array}$} \\
\hline Variables & Frequency & None & Occasionally & Daily & Each meal & & & \\
\hline \multirow{10}{*}{$\begin{array}{l}\text { Regurgitation } \\
\text { before operation }\end{array}$} & \multirow{2}{*}{ None } & 1 & 0 & 1 & 0 & 2 & \multirow{10}{*}{0.001} & \multirow{10}{*}{0.001} \\
\hline & & $3.2 \%$ & $0.0 \%$ & $3.2 \%$ & $0.0 \%$ & $6.5 \%$ & & \\
\hline & \multirow{2}{*}{ Occasionally } & 1 & 0 & 1 & 0 & 2 & & \\
\hline & & $3.2 \%$ & $0.0 \%$ & $3.2 \%$ & $0.0 \%$ & $6.5 \%$ & & \\
\hline & \multirow{2}{*}{ Daily } & 13 & 7 & 0 & 0 & 20 & & \\
\hline & & $41.9 \%$ & $22.6 \%$ & $0.0 \%$ & $0.0 \%$ & $64.5 \%$ & & \\
\hline & \multirow{2}{*}{ Each meal } & 5 & 2 & 0 & 0 & 7 & & \\
\hline & & $16.1 \%$ & $6.5 \%$ & $0.0 \%$ & $0.0 \%$ & $22.6 \%$ & & \\
\hline & \multirow{2}{*}{ Total } & 20 & 9 & 2 & 0 & 31 & & \\
\hline & & $64.5 \%$ & $29.0 \%$ & $6.5 \%$ & $0.0 \%$ & $100.0 \%$ & & \\
\hline \multirow{10}{*}{$\begin{array}{l}\text { Pain before } \\
\text { operation }\end{array}$} & \multirow{2}{*}{ None } & 8 & 1 & 0 & 0 & 9 & \multirow{10}{*}{0.046} & \multirow{10}{*}{0.047} \\
\hline & & $25.8 \%$ & $3.2 \%$ & $0.0 \%$ & $0 \%$ & $29.0 \%$ & & \\
\hline & \multirow{2}{*}{ Occasionally } & 8 & 5 & 1 & 0 & 14 & & \\
\hline & & $25.8 \%$ & $16.1 \%$ & $3.2 \%$ & $0 \%$ & $45.2 \%$ & & \\
\hline & \multirow{2}{*}{ Daily } & 0 & 3 & 2 & 0 & 5 & & \\
\hline & & $0.0 \%$ & $9.7 \%$ & $6.5 \%$ & $0 \%$ & $16.1 \%$ & & \\
\hline & \multirow{2}{*}{ Each meal } & 0 & 2 & 1 & 0 & 3 & & \\
\hline & & $0.0 \%$ & $6.5 \%$ & $3.2 \%$ & $0 \%$ & $9.7 \%$ & & \\
\hline & \multirow{2}{*}{ Total } & 16 & 11 & 4 & 0 & 31 & & \\
\hline & & $51.6 \%$ & $35.5 \%$ & $12.9 \%$ & $0 \%$ & $100.0 \%$ & & \\
\hline \multirow{11}{*}{$\begin{array}{l}\text { Dysphagia before } \\
\text { operation }\end{array}$} & \multirow{2}{*}{ None } & 0 & 0 & 0 & 0 & 0 & & \\
\hline & & $0.0 \%$ & $0.0 \%$ & $0.0 \%$ & $0.0 \%$ & $0.0 \%$ & & \\
\hline & \multirow{2}{*}{ Occasionally } & 0 & 0 & 0 & 0 & 0 & & \\
\hline & & $0.0 \%$ & $0.0 \%$ & $0.0 \%$ & $0.0 \%$ & $0.0 \%$ & & \\
\hline & & 4 & 10 & 0 & 5 & 19 & 0001 & 0001 \\
\hline & Da1ly & $12.9 \%$ & $32.3 \%$ & $0.0 \%$ & $16.1 \%$ & $61.3 \%$ & & 0.001 \\
\hline & Fach meal & 1 & 7 & 0 & 4 & 12 & & \\
\hline & Eacn meal & $3.2 \%$ & $22.6 \%$ & $0.0 \%$ & $12.9 \%$ & $38.7 \%$ & & \\
\hline & Total & 5 & 17 & 0 & 9 & 31 & & \\
\hline & lotal & $16.1 \%$ & $54.8 \%$ & $0.0 \%$ & $29.0 \%$ & $100.0 \%$ & & \\
\hline & & None & $<5 \mathrm{~kg}$ & $5-10 \mathrm{~kg}$ & $>10 \mathrm{~kg}$ & & & \\
\hline & Non & 3 & 1 & 0 & 0 & 4 & & \\
\hline & None & $9.7 \%$ & $3.2 \%$ & $0.0 \%$ & $0.0 \%$ & $12.9 \%$ & & \\
\hline & & 5 & 9 & 2 & 0 & 16 & & \\
\hline & $<5 \mathrm{~kg}$ & $16.1 \%$ & $29.0 \%$ & $6.5 \%$ & $0.0 \%$ & $51.6 \%$ & & \\
\hline Weight loss & $5-10 \mathrm{~kg}$ & 1 & 1 & 2 & 1 & 5 & & 0002 \\
\hline before operation & $5-10 \mathrm{~kg}$ & $3.2 \%$ & $3.2 \%$ & $6.5 \%$ & $3.2 \%$ & $16.1 \%$ & 0.002 & 0.002 \\
\hline & $>10 \mathrm{~kg}$ & 0 & 3 & 2 & 1 & 6 & & \\
\hline & $>10 \mathrm{~kg}$ & $0.0 \%$ & $9.7 \%$ & $6.5 \%$ & $3.2 \%$ & $19.4 \%$ & & \\
\hline & Total & 9 & 14 & 6 & 2 & 31 & & \\
\hline & Iotal & $29.0 \%$ & $45.2 \%$ & $19.4 \%$ & $6.5 \%$ & $100.0 \%$ & & \\
\hline
\end{tabular}


Table 3: Correlation between the disease outcome and frequency of balloon dilation, history of botulinum toxin injection, age, and sex

\begin{tabular}{|c|c|c|c|c|}
\hline Variables & Final Outcome & Treatment success * & Failure ** & $P$ value \\
\hline \multirow{2}{*}{$\begin{array}{l}\text { Pneumatic balloon } \\
\text { dilation }\end{array}$} & Number of case & 23 & 8 & \multirow{2}{*}{0.078} \\
\hline & Mean attempts & 1.90 & 2.73 & \\
\hline \multirow{2}{*}{$\begin{array}{l}\text { Botulinum toxin } \\
\text { injection }\end{array}$} & performed & 8 & 1 & \multirow{2}{*}{0.128} \\
\hline & Not performed & 15 & 7 & \\
\hline Age & Mean age & 35.50 & 35.70 & 0.870 \\
\hline \multirow{2}{*}{ Sex } & Male & 10 & 4 & \multirow{2}{*}{0.302} \\
\hline & Female & 13 & 4 & \\
\hline
\end{tabular}

$*$ Eckardt score $<4 \quad * *$ Eckardt score $\geq 4$

Table 4: Correlation between perforation and other variables

\begin{tabular}{|c|c|c|c|c|}
\hline \multirow{2}{*}{ Variables } & \multirow{2}{*}{ Levels } & \multicolumn{2}{|c|}{ Perforation } & \multirow{2}{*}{$P$ value } \\
\hline & & No $(n=31)$ & Yes $(n=5)$ & \\
\hline Age & Mean \pm SD & $36.65 \pm 13.50$ & $36.60 \pm 14.80$ & 0.760 \\
\hline \multirow{2}{*}{ Sex (No.) } & Female & 18 & 1 & \multirow{2}{*}{0.136} \\
\hline & Male & 13 & 4 & \\
\hline Duration between Botox and operation & Mean \pm SD & $1.24 \pm 4.67$ & $8.80 \pm 9.96$ & 0.006 \\
\hline Pneumatic balloon dilation & Mean \pm SD & $2.19 \pm 1.55$ & $1.20 \pm 1.30$ & 0.187 \\
\hline \multirow{2}{*}{ Botox (No.) } & No & 25 & 2 & \multirow{2}{*}{0.05} \\
\hline & Yes & 6 & 3 & \\
\hline NPO time & Mean \pm SD & $3.16 \pm 1.03$ & $5.00 \pm 1.22$ & 0.001 \\
\hline Antibiotic duration & Mean \pm SD & $1.19 \pm .54$ & $3.00 \pm 2.12$ & $<0.001$ \\
\hline Hospital stay & Mean $\pm \mathrm{SD}$ & $4.13 \pm .80$ & $6.40 \pm 3.20$ & 0.001 \\
\hline
\end{tabular}

In our study, eight patients $(25.8 \%)$ were not satisfied with the results of the procedure, of whom two underwent re-dilation with balloon, one was treated with botulinum toxin injection, and one received transthoracic open surgery. Other patients (four cases) did not accept to undergo any other treatment during the follow-up period, which may indicate their relative satisfaction.

The results of a study by Mikaeli and others who reviewed western and Iranian studies about achalasia, showed that myotomy was a very effective procedure and laparoscopic myotomy with fundoplication was the best surgical treatment for achalasia. However, compared with other non-surgical treatments, it costs more and has a longer recovery period. Myotomy is not recommended when surgery or anesthesia is contraindicated or when the center is not equipped for the surgery or postoperative care. According to the results of this study, graded pneumatic dilation is a safe and effective alternative for myotomy. We also perform pneumatic balloon dilation in two patients after Heller myotomy as an alternative method. ${ }^{16}$

We found no complications in 28 out of 36 patients (77.8\%). However, complications occurred in eight patients, including five cases of perforation. A significant positive correlation was seen between perforation and history of botulinum toxin injection $(p=0.05)$ and time interval between the last botulinum toxin injection and surgery $(p=0.009)$. In other words, a longer interval between botulinum toxin injection and surgery increased the odds of perforation. Moreover, perforation had a significant positive correlation with NPO time $(p=0.001)$, duration of antibiotic therapy $(p<0.001)$, and duration of hospital admission $(p=0.001)$. Krishnamohan reported that prior botulinum toxin injection did not increase the rate of perforation. ${ }^{17}$ While another study addressed preoperative botulinum toxin injection as a cause of difficult Heller myotomy, which is consistent with our results. ${ }^{18}$ That is why it has been suggested to consider an interval of at least 3 months after botulinum toxin injection and Heller myotomy. ${ }^{5}$ 
According to the results of a study by Torres-Villalobos and colleagues, medical treatment of achalasia is associated with a high rate of recurrence and failure, and LHM is the recommended procedure for initial treatment of achalasia. ${ }^{19}$

Almost $90 \%$ of the patients experienced improvement in the signs and symptoms of achalasia after Heller myotomy, and a considerable number of patients were asymptomatic during a long-term follow-up. Reoperation or PBD was recommended in a few the patients who experienced persistent symptoms or recurrence. ${ }^{11-15}$ Similarly, two patients in our study underwent PBD due to unsatisfactory results of the surgery.

According to the results of this study and previous studies, it seems that laparoscopic esophagocardiomyotomy improves the quality of life and symptoms in a large number of patients. Therefore, this procedure may be a suitable treatment option with acceptable results in new cases of achalasia or patients who do not respond to other treatment methods. On the other hand, to avoid mucosal perforation, injection of botulinum toxin should be reserved for cases not suitable for surgery such as older or pregnant patients. And when the injection is necessary, sufficient time interval to Heller myotomy should be considered. ${ }^{20,21}$

As mentioned above, different studies have been done to evaluate PBD and LHM and no superiority could be concluded for any of these. So we suggest using any of them according to the patient's and/or clinical conditions. ${ }^{22}$ LHM can be performed safely in complicated cases that were not improved by less invasive treatments such as botulinum injection or PBD with an acceptable final outcome.

The results of this study may be subjected to selection bias because Shariati Hospital is a tertiary referral center for achalasia and most patients are referred to the Hospital due to failure of previous treatments in other centers.

\section{ETHICAL APPROVAL}

There is nothing to be declared.

\section{CONFLICT OF INTEREST}

The authors declare no conflict of interest related to this work.

\section{REFERENCES}

1. Feldman M, Friedman LS, Brandt LJ. Gastroenterology: Sleisenger and Fordtran's gastrointestinal and liver disease: pathophysiology/diagnosis/management. JAMA 1998;279:715-6. doi:10.1001/jama.279.9.715-JBK0304-3-1.

2. Howard PJ, Maher L, Pryde A, Cameron EW, Heading RC. Five year prospective study of the incidence, clinical features, and diagnosis of achalasia in Edinburgh. Gut 1992;33:1011-5.

3. Stuart J Spechler M. Overview of the treatment of achalasia: UpToDate. Waltham, MA: UpToDate Inc.

4. Boeckxstaens GE, Zaninotto G, Richter JE. Achalasia. Lancet 2014;38:83-93. doi:10.1016/S0140-6736(13)60651-0.

5. Brunicardi F, Andersen D, Billiar T, Dunn D, Hunter J, Matthews J, et al. Schwartz's Principles of Surgery, 10th edition: McGraw-Hill Education; 2014.

6. Pandolfino JE, Kahrilas PJ. Presentation, Diagnosis, and Management of Achalasia. Clin Gastroenterol Hepatol 2013;11:887-97. doi:10.1016/j.cgh.2013.01.032.

7. Stefanidis D, Richardson W, Farrell T, Kohn G, Augenstein V, Fanelli R, et al. SAGES guidelines for the surgical treatment of esophageal achalasia. Surg Endosc 2012;26:296-311. doi:10.1007/s00464-011-2017-2.

8. Tsuboi K, Omura N, Yano F, Hoshino M, Yamamoto SR, Akimoto S, et al. Data analyses and perspectives on laparoscopic surgery for esophageal achalasia. World J Gastroenterol 2015;21:10830-9. doi:10.3748/wjg.v21.i38.10830.

9. Hasson HM. A modified instrument and method for laparoscopy. Am J Obstet Gynecol 1971;110:886-7. doi: 10.1016/0002-9378(71)90593-X.

10. Eckardt AJ, Eckardt VF. Treatment and surveillance strategies in achalasia: an update. Nat Rev Gastroenterol Hepatol 2011;8:311-9. doi:10.1038/nrgastro.2011.68.

11. Eckardt VF, Aignherr C, Bernhard G. Predictors of outcome in patients with achalasia treated by pneumatic dilation. Gastroenterology 1992;103:1732-8.

12. Hunter JG, Trus TL, Branum GD, Waring JP. Laparoscopic Heller Myotomy and Fundoplication for Achalasia. Ann Surg 1997;225:655-64.

13. Gockel I, Junginger T, Eckardt VF. Effects of Pneumatic Dilation and Myotomy on Esophageal Function and Morphology in Patients with Achalasia. Am Surg 2005;71:128-31

14. Moonen A, Annese V, Belmans A, Bredenoord AJ, Bruley des Varannes S, Costantini M, et al. Long-term results of the European achalasia trial: a multicentre randomised controlled trial comparing pneumatic dilation versus laparoscopic Heller myotomy. Gut 2016;65:732-9. doi: 10.1136/gutjnl-2015-310602. 
15. Popoff AM, Myers JA, Zelhart M, Maroulis B, Mesleh M, Millikan K, et al. Long-term symptom relief and patient satisfaction after Heller myotomy and Toupet fundoplication for achalasia. Am J Surg 2012;203:339-42. doi: 10.1016/j.amjsurg.2011.10.003.

16. Mikaeli J, Islami F, Malekzadeh R. Achalasia: A review of Western and Iranian experiences. World J Gastroenterol 2009;15:5000-9.

17. Krishnamohan P, Allen MS, Shen KR, Wigle DA, Nichols FC 3rd, Cassivi SD, et al. Long-term outcome after laparoscopic myotomy for achalasia. $J$ Thorac Cardiovasc Surg 2014;147:730-6. doi:10.1016/j.jtcvs.2013.09.063.

18. Zonca P, Cambal M, Labas P, Hrbaty B, Jacobi CA. The role of laparoscopic Heller myotomy in the treatment of achalasia. Bratisl Lek Listy 2014;115:156-60.

19. Torres-Villalobos G, Martin-del-Campo LA. Surgical Treatment for Achalasia of the Esophagus: Laparoscopic Heller Myotomy. Gastroenterol Res Pract 2013;2013:708327. doi:10.1155/2013/708327.

20. Abbes L, Leconte M, Coriat R, Dousset B, Chaussade S, Gaudric M. [Achalasia: role of endoscopic therapy and surgery]. Presse Med 2013;42:814-8. doi: 10.1016/j. lpm.2012.06.011.

21. Hooft N, Schmidt ES, Bremner RM. Achalasia in Pregnancy: Botulinum Toxin A Injection of Lower Esophageal Sphincter. Case Rep Surg 2015;2015:328970. doi: $10.1155 / 2015 / 328970$.

22. Chrystoja CC, Darling GE, Diamant NE, Kortan PP, Tomlinson GA, Deitel W, et al. Achalasia-Specific Quality of Life After Pneumatic Dilation or Laparoscopic Heller Myotomy With Partial Fundoplication: A Multicenter, Randomized Clinical Trial. Am J Gastroenterol 2016;111:1536-45. doi:10.1038/ajg.2016.402. 